\title{
Predictors of increased Fall Risk in Elderly patients Attending Outpatient Clinics
}

\author{
Heba M. Shaltoot, ${ }^{1}$ Fatima Haroun el Said ${ }^{1}$, Manar M. A. Maamoun ${ }^{1}$, Maram Maher ${ }^{1}$
}

${ }^{1}$ Geriatrics and Gerontology Department, Faculty of Medicine, Ain Shams University

\begin{abstract}
Background: Older people are more susceptible for fall. Fall is one of the most common geriatric syndromes that affects the quality of life of the elderly persons. It is the leading cause of severe injuries, as hip fractures in older population. Such injuries can result in "disability, chronic pain, loss of independence, poor quality of life, and in severe cases, death. Falls result from mix of biological, medical, behavioral or environmental risk factors.
\end{abstract}

Aim: to assess risk of falls in older people at outpatient clinics

Methods: A cross sectional study, 120 older adults were collected from outpatient clinics of Ain Shams Hospital. Geriatrics assessment was accomplished and fall risk assessment was completed using Morse fall scale (MFS) and timed up and go test (TUGT).

Results: The risk of falls was $41.67 \%$ and assessed by Morse Fall Scale among patients visiting ge riatrics outpatient clinics. Older age, cognitive decline, functional dependency, and use of antipsychotic were significant predictors of increased fall risk among elderly attending outpatient clinics.

Conclusion: We concluded that increased risk of falls in older adults attended outpatient clinics is multifactorial.

Keywords: Falls, Risk, Morse Fall Scale, Timed-up and go test.

\section{Background}

A fall can be defined as a sudden, unintentional change in position causing an individual to land at a lower level, on an object, the floor, or the ground, other than because of sudden onset of paralysis, epileptic seizure, or overwhelming external force. (1) Older adults often fall, causing a substantial burden on patients and the healthcare system at the same time. Falls and fallrelated injuries are a common and major problem among older adults. It is the leading cause of severe injuries, as hip fractures in older population. ${ }^{(2)}$ Also, the post-fall anxiety syndrome, fear of falling, is another consequence of falls, this in turn lead to deconditioning, weakness and gait problems and may actually increase risk of falls. ${ }^{(3)}$ Globally, falls are a major public health problem. The most prevalent fallrelated injuries among older adults are fractures of the hip, spine, upper arm, forearm, and bones of the pelvis, hand, and ankle. Of these, the most serious injury is hip fracture, a leading cause of morbidity and excess mortality among older adults. Older adults are hospitalized for fall-related injuries five times more often than they are for injuries from other causes, and women are nearly three times more likely than men to be hospitalized for a fall-related injury. ${ }^{(4)}$ It is a serious public health issue, with a substantial impact on health and healthcare costs. Elderly people attending geriatric outpatient clinics are a distinctive group that has different characteristics from those of the ordinary population or those in other institutions. Consequently, it is favorable to establish the profile of falls among the geriatric outpatient clinical population to establish care strategies for this group. ${ }^{(5)}$

\section{METHODS}

Study Design: Cross-sectional study was conducted in Ain-Shams University Hospital at outpatient clinics. The study included 120 older adults $\geq 60$ yrs. old (males and females) who attended outpatient clinics. All the patients were able to walk independently and their condition was stable. Patients who had acute illness or overt dementia were excluded.

METHODS: All participants were assessed regarding their demographic characteristics including age, gender, marital status, educational level and body mass index (BMI). Also, baseline data of participants were assessed as the presence of comorbidity or number of them $(\geq 3$ or $<3)$ and types of medications used or 
number of them.

Moreover, functional level was assessed as activities of daily living (ADL) ${ }^{(6)}$ and instrumental activities of daily living (IADL). ${ }^{(7)}$ Cognitive status was evaluated with Arabic version (8) of mini-mental status examination (MMSE). ${ }^{(9)}$

Risk of falls was assessed by Morse fall scale (MFS) (10) which is a fall assessment tool. It consists of 6 variables: History of falling (immediate or previous); secondary diagnosis $(\geq 2$ medical diagnoses $)$; ambulatory aid (none/bed rest/nurse assist, crutches/cane/walker and furniture); intravenous therapy/heparin lock; gait (normal/bed rest/wheelchair, weak and impaired) and mental status (oriented to own ability or overestimates/forgets limitations). There are three types of fall risk to be extracted from the final score: below 25 is considered low fall risk, 25-44 moderate and $\geq 45$ high fall risk.

Also, assessment of risk of fall was assessed with TUGT, ${ }^{(1)}$ patient got up out of an armchair seat height of approximately $46 \mathrm{~cm}$ (18.4 inch), and walked $3 \mathrm{~m}$ (10 ft.), then turned, walked back to the chair and sat down. The patient wore his regular footwear and, allowed to use any walking aid (e.g., cane or walker). No physical assistance was allowed. The time was taken used a wristwatch with a second hand. The interpretation of the TUGT ${ }^{(12)}$ is: $\leq 10$ seconds = Normal; 20 seconds $=$ Good mobility and can go without gait aid $\geq 30$ seconds $=$ can't go outside alone and require gait aid and a score of more than or equal 14 seconds has been shown to indicate high risk of falls.

Ethical Consideration: Informed oral consent was taken from every patient after explanation of the study aim and procedure and the study methodology was reviewed and approved by the Research Review Board of the Geriatrics and Gerontology Department, Faculty of medicine, Ain Shams University.

Statistical methods: Analysis of data was performed by using the Statistical Package for Social Science (SPSS16). Qualitative data were presented as numbers and percentages. The associations between variables and falls that occurred in the past 12 months were analyzed by the Chi-squared test.

\section{Results}

Description of the demographic data presented in [table 1] showed that the mean age of the participants was 71 yrs.; most of them were females $(60 \%)$ and $(40.00 \%)$ were males. Most of them were married (70.83\%) and $(60.0 \%)$ had less than 5 yrs. education. About $(72.5 \%)$ were overweight and $73 \%$ had less than 2 diseases.

The prevalence of increased risk of falls was about $41.67 \%$ divided into $31.67 \%$ and $10.0 \%$ with low and high risk respectively assessed by Morse Fall Scale among study population. (Figure 1)

Table (2) summarizes univariate analysis between different participants' variables and increased risk of falls assessed by (MFS). It shows that ageing and less than 5 years of education had highly statistical significant associated with increased risk of falls (MFS) $(\mathrm{p}<0.001 *)$.

Neither Number of drugs nor comorbidities had significant relation to risk of falls $(\mathrm{P}$-value $=0.760$, 0.105) respectively. However, Use of sedative hypnotics was statistically significant related to increased risk of falls $(\mathrm{P}$-value $=0.011 *)$.

Functional assessment by ADL/IADL was related to increased risk of falls both with (P-value <0.001) Also, Cognitive impairment by using MMSE was statistically significant associated with increased risk of falls (PV $\left.<0.001^{*}\right)$. Moreover, prolonged time in TUGT was associated with increased risk of falls $(\mathrm{PV}<0.001 *)$ in studied population. [Table 3]

The association between different risk factors and risk of falls (assessed by MFS) was evaluated using Logistic regression analysis. It was observed that IADL and prolonged TUGT scores were independent risk factors of falls after adjustment of other risk factors $(\mathrm{P}<0.001)$ as shown in [Table 4].

Table (1): Demographics and Baseline characteristics of studied population

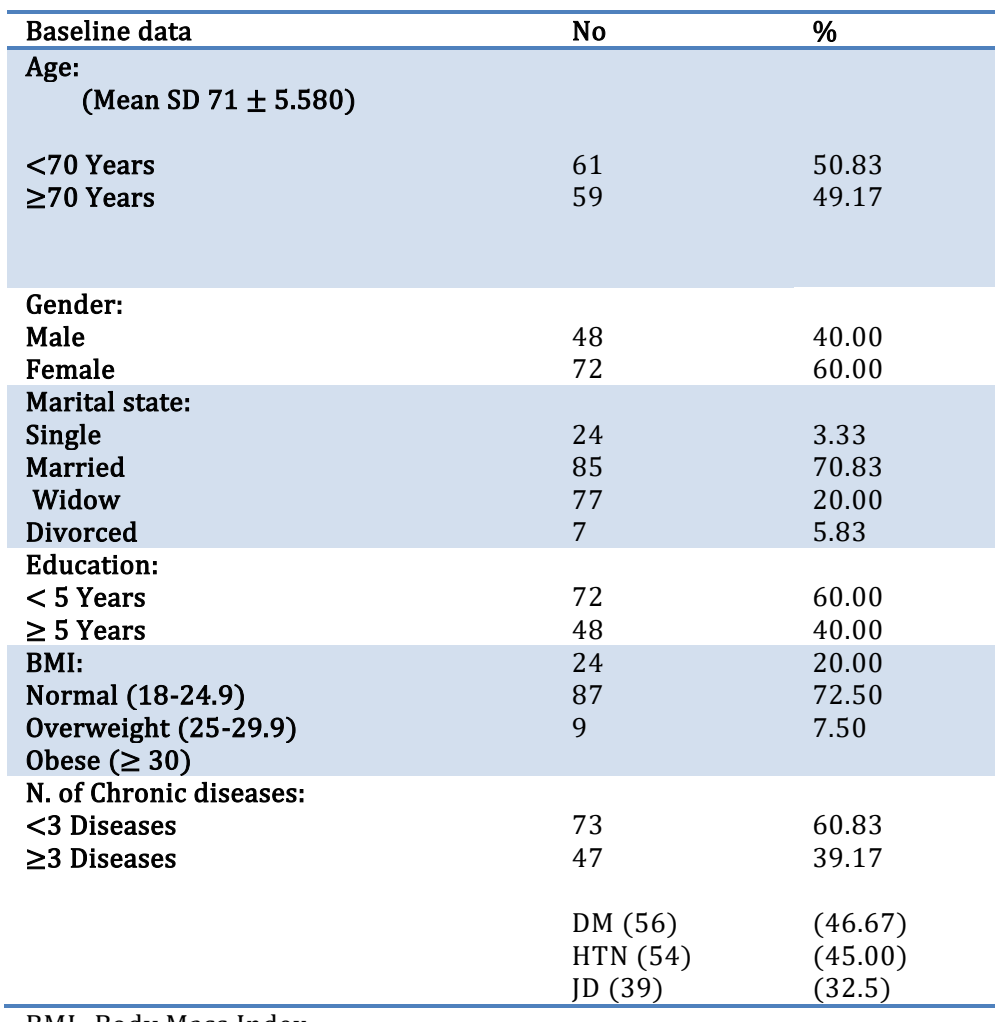

BMI- Body Mass Index. 
Shaltoot HM et al., EJGG.2020; 7(1):8-13

Table (1): Characteristics of the Studied Population:

\begin{tabular}{|c|c|c|c|c|c|c|c|c|c|c|c|}
\hline & \multicolumn{11}{|l|}{ Morse Fall Scale } \\
\hline & \multirow{2}{*}{$\begin{array}{l}\text { High } \\
\mathrm{N}\end{array}$} & \multirow{2}{*}{$\begin{array}{l}\text { Low } \\
\%\end{array}$} & \multicolumn{2}{|l|}{ Normal } & \multicolumn{2}{|l|}{ Total } & \multirow[b]{2}{*}{$\mathrm{N}$} & \multirow[b]{2}{*}{$\%$} & \multirow[b]{2}{*}{$\mathrm{X} 2$} & \multirow[b]{2}{*}{ P-value } & \\
\hline & & & $\%$ & & $\mathrm{~N}$ & & & & & & \\
\hline \multirow[t]{2}{*}{ Age } & $<70$ Years & 1 & 8.33 & 9 & 23.68 & 51 & 72.86 & 61 & 50.83 & \multirow[t]{2}{*}{33.464} & \multirow[t]{2}{*}{$<0.001^{*}$} \\
\hline & $>70$ Years & 11 & 91.67 & 29 & 76.32 & 19 & 27.14 & 59 & 49.17 & & \\
\hline \multirow[t]{2}{*}{ Gender } & Female & 7 & 58.33 & 25 & 65.79 & 40 & 57.14 & 72 & 60.00 & \multirow[t]{2}{*}{0.783} & \multirow[t]{2}{*}{0.676} \\
\hline & Male & 5 & 41.67 & 13 & 34.21 & 30 & 42.86 & 48 & 40.00 & & \\
\hline \multirow[t]{4}{*}{ Marital status } & Divorced & 0 & 0.00 & 2 & 5.26 & 5 & 7.14 & 7 & 5.83 & \multirow[t]{4}{*}{1.853} & \multirow[t]{4}{*}{0.933} \\
\hline & Married & 9 & 75.00 & 27 & 71.05 & 49 & 70.00 & 85 & 70.83 & & \\
\hline & Single & 0 & 0.00 & 1 & 2.63 & 3 & 4.29 & 4 & 3.33 & & \\
\hline & Widower & 3 & 25.00 & 8 & 21.05 & 13 & 18.57 & 24 & 20.00 & & \\
\hline \multirow[t]{2}{*}{$\begin{array}{l}\text { Educational } \\
\text { status }\end{array}$} & $\begin{array}{l}\text { Less than } 5 \\
\text { Years }\end{array}$ & 12 & 100.00 & 32 & 84.21 & 28 & 40.00 & 72 & 60.00 & \multirow[t]{2}{*}{28.947} & \multirow[t]{2}{*}{$<0.001^{*}$} \\
\hline & $\begin{array}{l}\text { More than } 5 \\
\text { Years }\end{array}$ & 0 & 0.00 & 6 & 15.79 & 42 & 60.00 & 48 & 40.00 & & \\
\hline \multirow[t]{3}{*}{ BMI } & Normal & 3 & 25.00 & 13 & 34.21 & 8 & 11.43 & 24 & 20.00 & \multirow[t]{3}{*}{9.245} & \multirow[t]{3}{*}{0.055} \\
\hline & Overweight & 9 & 75.00 & 22 & 57.89 & 56 & 80.00 & 87 & 72.50 & & \\
\hline & Obese & 0 & 0.00 & 3 & 7.89 & 6 & 8.57 & 9 & 7.50 & & \\
\hline \multirow{8}{*}{$\begin{array}{l}\text { N. of Chronic } \\
\text { diseases } \\
\text { Medication } \\
\text { uses }\end{array}$} & $<3$ Diseases & 4 & 33.33 & 23 & 60.53 & 46 & 65.71 & 73 & 60.83 & 4.510 & 0.105 \\
\hline & $\geq 3$ Diseases & 8 & 66.67 & 15 & 39.47 & 24 & 34.29 & 47 & 39.17 & & \\
\hline & Antidepressants & 1 & 8.33 & 0 & 0.00 & 2 & 2.86 & 3 & 2.50 & 2.686 & 0.261 \\
\hline & $\begin{array}{l}\text { Antihypertensiv } \\
\text { e }\end{array}$ & 6 & 50.00 & 15 & 39.47 & 28 & 40.00 & 49 & 40.83 & 0.467 & 0.792 \\
\hline & $\begin{array}{l}\text { Sedative } \\
\text { hypnotics }\end{array}$ & 1 & 8.33 & 1 & 2.63 & 5 & 7.14 & 7 & 5.83 & 1.064 & 0.587 \\
\hline & Antipsychotics & 1 & 8.33 & 0 & 0.00 & 0 & 0.00 & 1 & 0.83 & 9.076 & $0.011^{*}$ \\
\hline & Diuretics & 2 & 16.67 & 5 & 13.16 & 15 & 21.43 & 22 & 18.33 & 1.150 & 0.563 \\
\hline & $\begin{array}{l}\text { Benzodiazepine } \\
\mathrm{s}\end{array}$ & 0 & 0.00 & 1 & 2.63 & 1 & 1.43 & 2 & 1.67 & 0.443 & 0.801 \\
\hline No. of drugs & Two & 3 & 25.00 & 8 & 21.05 & 15 & 21.43 & 26 & 21.67 & 4.979 & 0.760 \\
\hline & Three & 5 & 41.67 & 14 & 36.84 & 16 & 22.86 & 35 & 29.17 & & \\
\hline & Four & 2 & 16.67 & 8 & 21.05 & 19 & 27.14 & 29 & 24.17 & & \\
\hline & Five & 2 & 16.67 & 7 & 18.42 & 15 & 21.43 & 24 & 20.00 & & \\
\hline & Six & 0 & 0.00 & 1 & 2.63 & 5 & 7.14 & 6 & 5.00 & & \\
\hline ADL & Independent & 4 & 33.33 & 33 & 86.84 & 69 & 98.57 & 106 & 88.33 & 42.42 & $<0.001^{*}$ \\
\hline & Assisted & 8 & 66.67 & 5 & 13.16 & 1 & 1.43 & 14 & 11.67 & 5 & \\
\hline IADL & Independent & 0 & 0.00 & 13 & 34.21 & 70 & 100.00 & 83 & 69.17 & 128.4 & $<0.001^{*}$ \\
\hline & Assisted & 0 & 0.00 & 18 & 47.37 & 0 & 0.00 & 18 & 15.00 & 10 & \\
\hline & Dependent & 12 & 100.00 & 7 & 18.42 & 0 & 0.00 & 19 & 15.83 & & \\
\hline MMSE & $\begin{array}{l}\text { Cognitive } \\
\text { impairment }\end{array}$ & 6 & 50.00 & 2 & 5.26 & 0 & 0.00 & 8 & 6.67 & $\begin{array}{l}41.33 \\
5\end{array}$ & $<0.001^{*}$ \\
\hline & Normal & 6 & 50.00 & 36 & 94.74 & 70 & 100.00 & 112 & 93.33 & & \\
\hline
\end{tabular}

Table (3): Relation between TUGT increased risk of falls assessed by (MFS).

\begin{tabular}{|c|c|c|c|c|c|c|c|c|c|c|c|c|}
\hline & & \multicolumn{9}{|c|}{ Morse Fall Scale } & \multirow{2}{*}{\multicolumn{2}{|c|}{$\begin{array}{l}\text { Chi-Square or } \\
\text { ANOVA }\end{array}$}} \\
\hline & & \multicolumn{3}{|l|}{ High } & \multicolumn{3}{|l|}{ Low } & \multicolumn{3}{|l|}{ Normal } & & \\
\hline & & $\mathrm{N}$ & & $\%$ & $\mathrm{~N}$ & & $\%$ & $\mathrm{~N}$ & & $\%$ & $\mathrm{X} 2$ or $\mathrm{F}$ & P-value \\
\hline \multirow[t]{4}{*}{ TUGT } & abnormal & 12 & & 100.00 & 34 & & 89.47 & 17 & & 24.29 & \multirow[t]{2}{*}{54.034} & \multirow[t]{2}{*}{$<0.001^{*}$} \\
\hline & normal & 0 & & 0.00 & 4 & & 10.53 & 53 & & 75.71 & & \\
\hline & Range & 34 & - & 73 & 12 & - & 56 & 11 & - & 38 & \multirow[t]{2}{*}{104.474} & \multirow[t]{2}{*}{$<0.001^{*}$} \\
\hline & Mean \pm SD & 49.000 & \pm & 11.037 & 30.316 & \pm & 8.847 & 17.771 & \pm & 5.751 & & \\
\hline
\end{tabular}


Figure (1): MFS-Morse Fall Scale

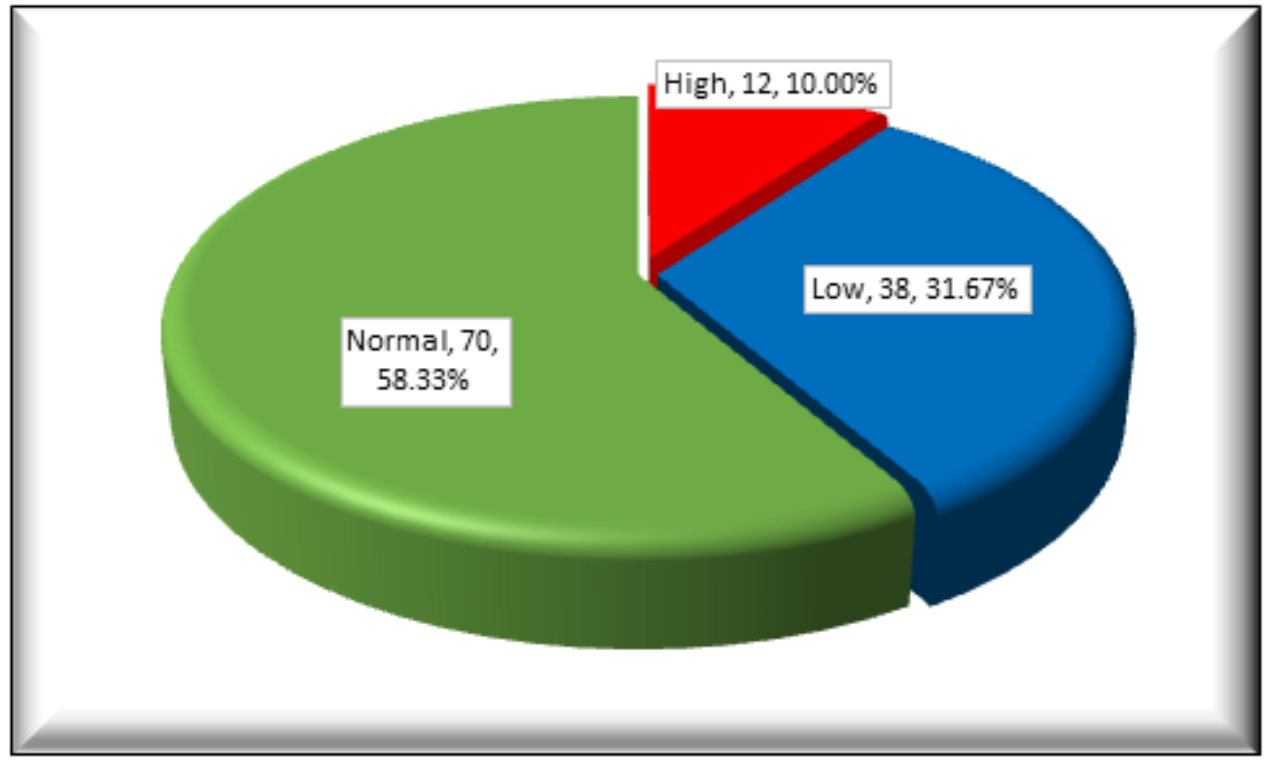

Table (4): Logistic regression analysis of risk of falls

\begin{tabular}{|c|c|c|c|c|c|}
\hline & \multicolumn{2}{|c|}{ Unstandardized Coefficients } & \multirow{2}{*}{$\begin{array}{l}\text { Standardized } \\
\text { Coefficients } \\
\text { Beta }\end{array}$} & \multirow[t]{2}{*}{$\mathrm{t}$} & \multirow[t]{2}{*}{ P-value } \\
\hline & B & Std. Error & & & \\
\hline Age (Years) & 0.133 & 0.171 & 0.051 & 0.776 & 0.439 \\
\hline Educational status & -1.283 & 1.710 & -0.043 & -0.750 & 0.455 \\
\hline Cognitive impairment & -0.831 & 3.519 & -0.013 & -0.236 & 0.814 \\
\hline ADL & 2.723 & 3.038 & 0.060 & 0.896 & 0.372 \\
\hline IADL & 8.440 & 1.266 & 0.439 & 6.664 & $<0.001^{*}$ \\
\hline TUGT & 0.469 & 0.103 & 0.399 & 4.540 & $<0.001^{*}$ \\
\hline
\end{tabular}

\section{Discussion}

The risk of falls has been assessed in geriatric outpatients and it was shown that fall risk was about $42 \%$ of the studied population. Many factors were significantly associated with increased risk of fall including aging, low educational level, cognitive impairment and more importantly impaired function.

The present study found that cases with functional impairment (assisted/dependent) in ADL \& IADL had significant association with increased risk of falls which was consistent with a prospective follow up study 1779 inpatients admitted to Ain Shams university hospitals. They found that elderly fallers had impaired ADL and IADL scores in comparison to non-fallers.
"Being dependent" in instrumental daily activities, was one of the independent risk factors of falling among elderly. ${ }^{(13)}$

Regarding age, the current study showed that, there was a statistically significant association between chronological age and the increased risk of falls. Aging is associated with decline in multiple physiological systems including visual, vestibular musculoskeletal, cardiovascular, slowed postural responses, proprioception, coordination, and cognitive function ${ }^{(14)}$ Many studies reported that falls increase with age. ${ }^{(15)}$ (16) These disagreed with a cross-sectional study conducted in Longtan Community, Beijing. A total of 
1512 individuals aged 60 years or over were selected. The prevalence of falls was $18.0 \%$ on the average among 1512 participants, higher in women (20.1\%), this difference may be due to larger study sample and the history of fall was restricted to the previous year only. ${ }^{(17)}$

The findings regarding the gender, as with some previous studies, the falls prevalence increased with age among both genders. This might be attributed to age-induced declines in physical, sensory, and cognitive function, as well as an increase in the number of comorbid conditions. ${ }^{(18)}$ Another study conducted in Germany; the fall rates increased with age in men but not women. (19) The opposite was found in Nigeria where women were more likely than men to report falls. ${ }^{(20)}$ These different findings in different countries between elderly men and women could be related to unmeasured biological, social or environmental characteristics.

As for marital status, the result agreed with Kamel et al. (2013) who found that there was no statistical difference as regard educational level or marital status among fallers and non-fallers. ${ }^{(21)}$ However, a study conducted on the risk factors of home injury among elderly people in Malaysia found that fewer married elderly people $(4.9 \%)$ were likely to experience injuries at home than divorced/widowed $(8 \%)$ or single elderly people $(8 \%)^{(22)}$ and might be explained by the benefits of marriage with regard to health behaviors, such as diet and physical activity level.

The findings showed that the frequency of falls was inversely related to patient's educational levels, which may be an important risk factor for falls. In comparison with a study done regarding the effect of lower education levels on increased risk of falling, showed that the risk increased among the uneducated elderly. (23) This could be explained by the lack of resources to learn information on how to prevent injuries. The lack of the knowledge therefore leads to the absence of preventive measures and activities. This disagreed with who found that there was no statistical difference as regard educational level or marital status among fallers and non-fallers. ${ }^{(21)}$

In the current study, BMI had no add difference on risk of falls as previous studies, indicated that increased BMI adds no risk of falls. ${ }^{(24)}$ Overweight and obese older adults have been shown to adopt a more tentative gait pattern, with a slower walking velocity and an increased base of support. (25) As a result of these adaptations, stability is in fact improved. (26) These alterations may inadvertently represent a protective effect against falls. In addition, those with obesity were more likely to meet the reduced physical activity frailty criterion. This would suggest that adults with obesity present with less opportunity to fall as they are less physically active. However, a relationship between obesity in the elderly and falls has been shown, and it has been proposed that a lower BMI leads to a higher risk of severe injury. ${ }^{(27)}$

Regarding Medications used, the current study found that, there was no significant association between the number of medications used (polypharmacy) and increased risk of falls but there was significant association between the type of drugs used as antipsychotics and increased risk of falls. The other studies identified links between medications used and increased risk of falls that was associated either with the type of medications taken or, as in some situations were linked with an increase in the number of medications used per day. (28)

The current study demonstrated that number of chronic diseases had no significant association with increased risk of falls. Although this result disagreed with other studies as a systematic review of observational studies on risk factors for falls in community-dwelling older people showed that certain health conditions and impairments contribute independently to the risk of falls or experiencing a fall injury. (29)

In the current study, cases with cognitive impairment in MMSE had significantly increased risk of falls. Walking requires paying attention to various environmental features to avoid trips and slips and quickly recovering from postural perturbations to regain a stable base of support. Previous studies have also shown that older adults with cognitive impairment have a higher prevalence of gait impairment and higher risk of falling than cognitively normal older adults. ${ }^{(30)(31)(32)(33)}$ Thus, older adults with MCI are a population at risk, not only for future dementia, but also for falls, and should perhaps be specifically targeted for interventions to reduce fall risk.

In the current study, cases with prolonged time in TUGT had significantly increased risk of falls. In a sixmonth prospective cohort study involved frail elderly individuals living in long-stay institutions in Sweden, found that a performance on the TUGT greater than 15 seconds identified the risk of falls with $96 \%$ sensitivity and $32 \%$ specificity. $^{(34)}$

Conclusion: The results allow the conclusion that elderly people with worse physical performance and less independence in motor tasks especially in IADL and those with prolonged TUGT present a higher risk of fall.

Recommendation: Identifying factors related to falls among elderly is important in helping to detect the risks of occurrences of falls, as well as for proposing strategies for preventive care and/or rehabilitation among elderly people who have already suffered falls. 


\section{References}

1. Feder G, Cryer C, Donovan S, et al., (2000): Guidelines for the prevention of falls in people over 65. BMJ; 321(7267): 1007-1011.

2. Edwards $M H$, Jameson K, Denison H, Harvey NC., Sayer AA, Dennison $E M$, et al., (2013): Clinical risk factors, bone density and fall history in the prediction of incident fracture among men and women. Bone; 52: 541-547. 3.Tanimoto $Y$, Watanabe $M$, Sun W, Sugiura , et al., (2014): Sarcopenia and falls in community-dwelling elderly subjects in Japan : Defining sarcopenia according to criteria of the European Working Group on Sarcopenia in Older People. Arch Gerontol Geriatr.; 59(2):295-9.

4. Bradley SM (2011): Falls in older adults. Mt Sinai J Med. 2011 Jul-Aug; 78(4):590-5. PMID: 21748747

5. Gomes GA, Cintra FA, Batista FS et al,(2013) Elderly outpatient profile and predictors of falls. Sao Paulo Med J. 2013; 131(1):13-8.

6. Katz S, Ford AB, Moswowitz RW, Jackson BA \& Jaffe MW (1963): Studies of illness in the aged. The index of ADL: Standardized measure of biological and psychological function. JAMA; 185-914.

7. Lawton MP \& Brody EM (1969): Assessment of older people: Selfmaintaining and instrumental activities of daily living. The Gerontologist; 9(3), 179-186.

8. El OkI MA, El-Banouby MH, Eletrby MA, Mortagy AK \& Elsaied, MN. (2002): Prevalence of Alzheimer dementia and other causes of dementia in Egyptian elderly. MD thesis, Faculty of Medicine, Ain Shams University.Geriatric Department Library.

9. Folstein MF, Folstein SE \& McHugh PR (1975): Mini-mental state, a practical method for grading the cognitive state of patients for the clinician. J Psychiatr Res.; 12(3):189-98.

10. Morse JR \& Tylko S (1989): Development of a scale to identify the fallprone patient. Can J Agin; 8:366-7.

11. Podsiadlo, D. \& Richardson, S. (1991): The timed 'Up \& Go': A test of basic functional mobility for frail elderly persons. Journal of the American Geriatrics Society; 39 (2):142-48.

12. Shumway, CA., Brauer, S. \& Woollacott, M. (2000): predicting the probability for falls in community dwelling older adults Using Timed up \& Go test. Physical therapy; 80 (9): 896-903.

13. Bakr IM, Abd Elaziz KM, Elgaafary MM et al. (2011): Epidemiologic pattern of falls among inpatients in Ain Shams University Hospitals in Cairo, Egypt. J prev med hyg; 52(1): 32-37.

14. Segev-Jacubovski O, Herman T, Yogev-Seligmann G, et al., (2011): The interplay between gait, falls and cognition: can cognitive therapy reduce fall risk? Expert Rev Neurotherap; 11(7): 1057-75.

15. Bird ML, Pittaway JK, Cuisick I, et al., (2013): Age-related changes in physical fall risk factors: results from a 3year follow-up of community dwelling older adults in Tasmania, Australia. Int $J$ Environ Res Public Health 2013; 10:5989-97.

16. linattiniemi S, Jokelainen J, \& Luukinen H (2009): Falls risk among a very old home-dwelling population. Scand J Prim Health Care; 27:25-30.

17. Pu-Lin YU, Zhao-Hui Q, Jing S, Juan Z, et al., (2009): Prevalence and
Related Factors of Falls among the Elderly in an Urban Community of Beijing. Biomedical and Environmental Science; 22(3):179-187.

18. Ambrose AF, Paul G, Hausdroff JM (2013): Risk factors of falls among olders adults. Maturitasm ; 75:51-61.

19. Rapp, K., Freiberger, E., Todd, C., et al., (2014): Fall incidence in Germany: results of two population-based studies, and comparison of retrospective and prospective falls data collection methods. BMC Geriatr; 14:105.

20. Bekibele, CO. \& Gureje, O. (2010): Fall incidence in a population of elderly persons in Nigeria. Gerontology; 56:278-83.

21. Kamel, MH., Abdulmajeed, A. \& Ismail, SE. (2013): Risk factors of falls among elderly living in Urban Suez - Egypt. Pan Afr Med J; 14:26.

22. Lim, K., Jasvindar, K., Normala, I., et al., (2013): Risk factors of home injuryamong elderly people in Malaysia. Asian J Gerontol Geriatr; 8.

23. Kumar, A., Carpenter, H., Morris, R., et al., (2014): Which factors are associated with fear of falling in community-dwelling older people? Age Ageing; 43:76-84.

24. Rosenblatt NJ \& Grabiner MD (2012): Relationship between obesity and falls by middle-aged and older women. Arch Phys Med Rehabil. 2012; 13:718-722

25. Ko, S., Stenholm, S. \& Ferrucci, L. (2010): Characteristic gait patterns in older adults with obesity - results from the Baltimore longitudinal study of aging. J Biomech. 2010; 13:1104-1110.

26. Menz, HB., Lord, SR. \& Fitzpatrick, RC. (2003): Age-related differences in walking stability. Age Ageing. 2003; 13:137-142.

27. Tinetti ME, John D, Elizabeth C \& Richard M (1995): Risk Factors for Serious Injury During Falls by Older Persons in the Community. Journal of The American Geriatrics Society.

28. Kojima, T., Akishita, M., Nakamura, T., et al., (2012): Polypharmacy as a risk for fall occurrence in geriatric outpatients. Geriatr Gerontol Int.; 12(3):425-30.

29. Tinetti ME \& Kumar C (2010): The patient who falls: "It's always a trade-off." JAMA; 303(3): 258-266.

30. Liu-Ambrose TY, Ashe MC, Graf, $P$, et al., (2008): Increased risk of falling in older community-dwelling women with mild cognitive impairment. Phys Ther . 1491-2008; 88: 1482

31. Verghese J, Robbins $M$, Holtzer $R$, et al., (2008): Gait dysfunction in mild cognitive impairment syndromes. J Am Geriatr Soc 2008; 56: 1244 1251.

32. Montero-Odasso M, Bergman H, Phillips NA, et al., (2009): Dual-tasking and gait in people with mild cognitive impairment. The effect of working memory. BMC Geriatr 2009; 9: 41.

33. Delbaere K, Kochan NA, Close JC, et al., (2012): Mild cognitive impairment as a predictor of falls in community-dwelling older people. Am $J$ Geriatr Psychiatry 853. -2012; 20: 845

34. Nordin E, Lindelöf $N$, Rosendahl E, Jensen Jand Lundin-Olsson $L$ (2008): Prognostic validity of the Timed Up-and-Go Test, a modified Get Up-and-Go Test, staff's global judgement and fall history in evaluating fall risk in residential care facilities. Age Ageing. 2008;37(4):442-8. 